九州大学学術情報リポジトリ

Kyushu University Institutional Repository

Descriptions of a New Genus and a New Species of the Tribe Batrisini from Japan (Coleoptera, Pse laphidae)

Nomura, Shuhe i

https://doi.org/10.5109/2586

出版情報: ESAKIA. 35，pp.123-128，1995-01-31. Entomological Laboratory，Faculty of Agriculture, Kyushu University バージョン :

権利関係 : 


\title{
Descriptions of a New Genus and a New Species of the Tribe Batrisini from Japan (Coleoptera, Pselaphidae)1)
}

\author{
Shûhei NOMURA \\ Entomological Laboratory, Faculty of Agriculture \\ Kyushu University, Fukuoka, 812 Japan
}

\begin{abstract}
Babascenellus macroscapus gen. et sp. nov. is described in the tribe Batrisini from Japan, with discussion of the systematic position and illustration of important characters.
\end{abstract}

The Batrisocenus complex defined by Nomura (1991) is a monophyletic group in the subfamily Batrisinae comprising 20 genera and more than 300 species in the Oriental and Ethiopian regions, and 6 genera and 68 species from Japan. A new genus and a new species of this group are newly described and the systematic position of this genus is discussed.

\section{Babascenel lus gen. nov.}

Type species: Babascenellus macroscapus sp. nov.

Body medium-sized, elongate, narrowed on head and pronotum, sparsely punctate on dorsal surface and shiny. Head nearly pentagonal on dorsal view, postgenae very short; eyes welldeveloped; antennae elongate, 1st segment predominantly large and thick (Fig. 3A), dilated apically and projected laterally in both sexes, 2nd to 8th slender, 9th to 11th successively thickened apically. Pronotum convex, rounded on both sides, with 3 longitudinal and a transverse sulci; elytra weakly broadened posteriorly, each eiytron with 2 basal and a lateral foveae and a longitudinal sulcus; legs thick in femora, hind femora each with setiferous patch on outer side in male, tibiae and tarsi very slender. Abdomen short and rounded posteriorly in male, 4th segment very large, 9th sternite externally visible in male, invisible in female. Male genitalia composed of reduced parameres and well-sclerotized median lobe, median lobe composed of a large basal bulb with a slender ventral stalk, and curved and bifurcate dorsal apophysis. Female genitalia (ovipositor) consisting of T-shaped 9th abdominal stemite and Wshaped small genital plate.

1) Contribution from the Entomological Laboratory, Faculty of Agriculture, Kyushu University, Fukuoka (Ser. 4, No. 81). 
Systematic position. The genus Babascenellus is a member of the monophyletic group including Batriscenellus, typical Arthromelus and Seydelites, of which latter two genera are known from Africa, and the group is defined by a synapomorphic character, "the dorsal apophysis of the male genitalia is curved at the basal part" (Nomura, 1991). But the present new genus is separated from the other three genera by lacking the synapomorphy of them, "the first antennal segment is with a conical setiferous organ". This genus is unique by having the other apomorphic character that the first antennal segment is strongly thickened apically and projected laterally with a small spine at apical side of the projection (Fig 3B). On the other hand, this genus is similar to Batriscenellus (Batriscenellinus) uenoi Nomura, Physomerinus spp. and Batriscenaulax kleinzach Nomura in having the setiferous patch on the hind femur (Fig. 3C). But it is apparent that the patch of Babascenellus is different from those of the other groups in the secretory setae each of which consists of the ring-shaped basal concavity, the long and tubular basal socket and the broadened apical lobe as shown in Fig. 3D. The systematic position of this genus is therefore, inferred as shown in the cladogram of Fig. 1.

Etymology. The genus name is constituted of the suffix from the generic name, "-scenellus" and the prefix "Baba-" from the late Dr. Kintaro Baba in commemoration of his great contribution to Japanese coleopterology and his kind assistance to our study.

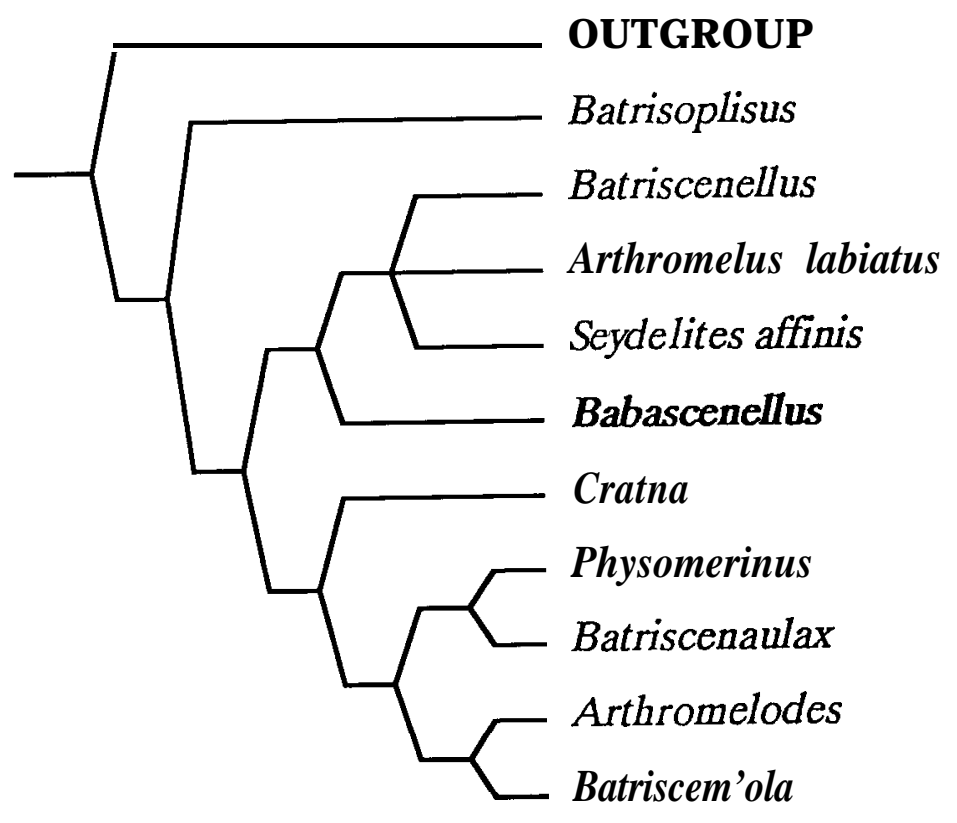

Fig. 1. Phylogenetic position of the new genus Babascenellus in the Batrisocenus complex. 


\section{Babascenellus macroscapus sp. nov.}

Male (Fig. 2). Length $2.7 \mathrm{~mm}$. Width $1.0 \mathrm{~mm}$.

Body reddish brown, maxillary palpi and tarsi light brown, elongate and narrowed on anterior part.

Head longer than wide, subparallel-sided, clypeus short, arcuate on anterior margin, frons concave in median part, coarsely punctate in both lateral parts, with a short transverse sulcus behind the median concavity, vertex weakly convex, with a pair of dorsal tentorial pits and a me-

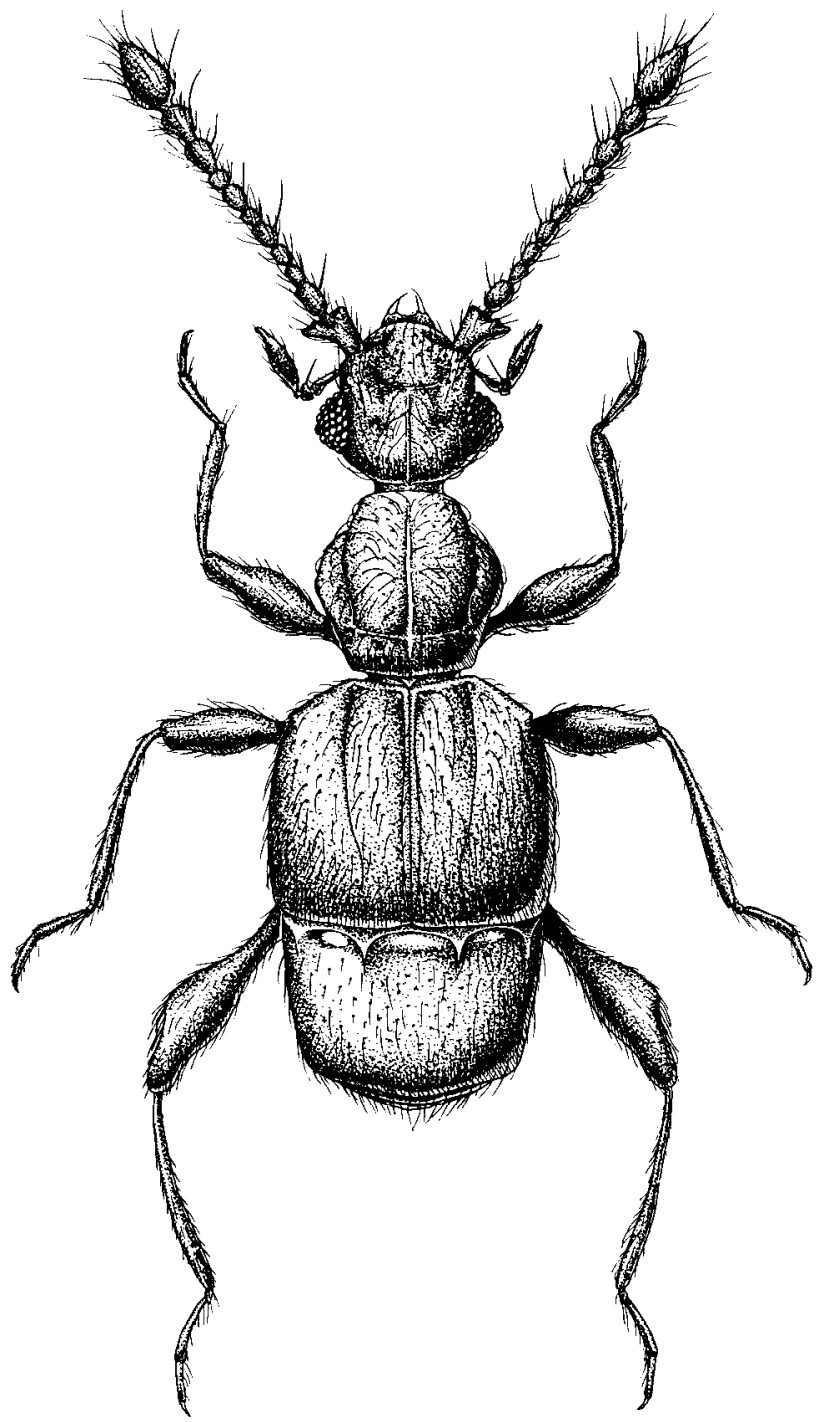

Fig. 2. Dorsal aspect of the male of Babascenellus macroscapus gen. et sp. nov. 
dian longitudinal carina running from the frontal transverse sulcus to cervical constriction, postgenae very short and flat. Eyes each ovoid and convex, composed of about 25 facets. Antennae reaching base of elytra, 1st segment widest and very thick, dilated distally, strongly projected laterally, with a small spine at inside of the lateral projection, 2nd half as wide as 1st, longer than wide and ovoid, 3rd to 8th subequal in width, each smaller than 2nd, longer than wide and thickened distally, 9th to 1 lth each thick and ovoid, 1 lth largest, Maxillary palpi short, 1st tubular and curved, 2nd strongly thickened in apical half, 3rd short and triangular, 4th largest, 2.5 times as long as wide, fusiform.

Pronotum as long as wide, rounded on both sides, with a median and a pair of longitudinal sulci and a transverse sulci at basal 1/4, sparsely with minute punctures. Elytra wider than long, nearly trapezoid and convex, humeri well-projected, each with a small denticle, each elytron with 2 basal and a lateral foveae, longitudinal sulcus running from outer basal fovea to posterior $1 / 5$. Legs elongate, femora thick, hind femora each shallowly excavated on apical $2 / 5$ on outer side, with a large setiferous patch at the excavation (Fig 3C, D), tibiae very slender, mid tibiae each with a very short mucro at apex.

Abdomen shorter than elytra, 4th segment predominantly large, 5th to 6th very short, subequal in length in posterior view, 7th larger than 5 th +6 th, 8 th tergite slightly transverse, shallowly emarginate at the middle of hind margin, 8th stemite short and crescent, 9th stemite small and nearly semicircular.
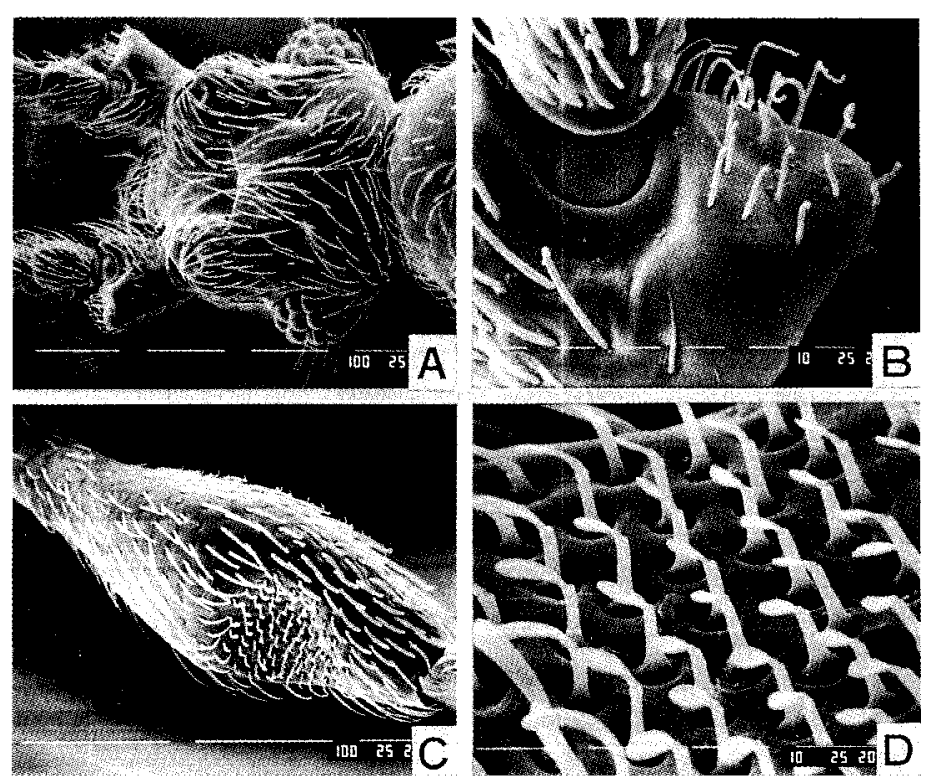

Fig. 3. A-B: Babascenellus macroscapus gen. et sp. nov., female; C-D: ditto, male. A: head; B: 1st antennal segment; C: hind femur; D: secretory setae of hind femur. 

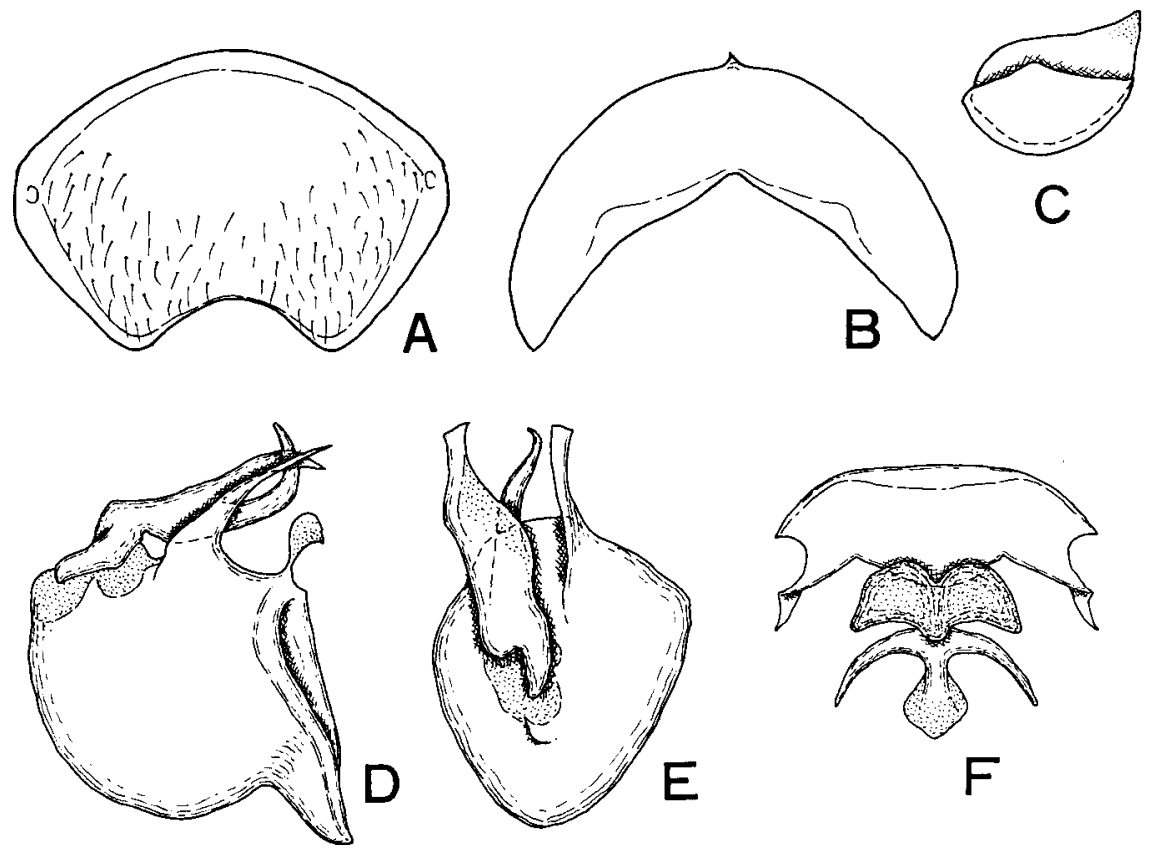

Fig. 4. A-E: Babascenellus macroscapus gen. et sp. nov., male; F: ditto, female. A: 8th abdominal tergite; B: 8th sternite; C: 9th sternite; D: aedeagus in lateral view; E: ditto, in dorsal view; F: 9th sternite and genital plate.

Male genitalia well-sclerotized, parameres small, ovoid and lamellar, basal bulb of median lobe very large, strongly projected at base of basal foramen, with an acuminate ventral stalk and a very short articulate process, dorsal apophysis short, bent at base, bifurcate at apex, right spine short and truncate at apex, left spine long, acute at apex, distally curved to reach apical part of ventral stalk.

Female. Length $2.6-2.8 \mathrm{~mm}$. Width $0.9-1.0 \mathrm{~mm}$.

Very similar to male, but eyes each smaller than in male, composed of about 20 facets; elytra shorter than in male; hind femur almost flat on outer side without secretory setae, mid tibia slender, truncate at apex; 8th abdominal stemite larger than in male, semicircular. Ninth stemite composed of large and well-sclerotized apical lobe and small and membranous basal lobe, apical lobe transverse, deeply emarginate on both sides, thickened on apical and basal margins; genital plate strongly sclerotized, small and W-shaped, acute at apices of lateral arms.

Distribution. Japan: Honshu (?), Ryukyu Isls. (Miyako, Ishigaki, Iriomote, Hateruma and Yonaguni Isls.).

Holotype, male (Type No. 2993, Kyushu Univ.), Mt. Omotodake, Ishigaki Is., Okinawa Pref., 9. iv. 1986, S. Nomura leg. Paratypes: 1 male, Noo, S-Echigo, Niigata Pref., 27. iii. 1983, K. Baba leg. (see remarks); 4 males, Hirara, Miyako Is., Okinawa Pref., 29. iv. 1971, B. Melin leg.; 3 females, same locality as holotype, 17. iii. 1978, H. Ohishi leg.; 1 male, Yonehara, Ishigaki Is., Okinawa Pref., 1. iv. 1982, S. Tanaka leg.; 2 males 1 female, same locality as above, 14. iv. 
1992, K. Ogata leg.; 1 male 2 females, Mt. Bannadake, Ishigaki Is., Okinawa Pref., 15. iii. 1978, H. Ohishi leg.; 1 female, same locality as above, 13. ii. 1984, J. Nakata leg.; 21 males 6 females, same locality as above, 20-21. iv. 1992, H. Kojima leg.; 5 males 3 females, same locality as above; 20 iv. 1993, H. Kojima leg.; 1 male 1 female, Mt. Bansedake, Ishigaki Is., Okinawa Pref., 4. ix. 1989, collector unknown; 1 male, Hirakubo, Ishigaki Is., Okinawa Pref., 19. iii. 1993, S. Nomura leg.; 1 female, Shiromizu, Ishigaki Is., Okinawa Pref., 6. v. 1993, K. Ogata leg.; 1 female, Funaura, Iriomote Is., 15. x. 1988, S. Nomura leg.; 3 males 1 female, Buribuchi Park, Hateruma Is., Okinawa Pref., 17. iv. 1993, H. Kojima leg.; 1 female, Hikawa-Sonai, Yonaguni Is., 3. viii. 1992, K. Ogata leg.

Remarks. This species is similar to some of Batriscenellus in the aspect, but is easily distinguished by the large and apically dilated first antennal segment. Though only one male was collected from Niigata, Honshu, it is considered to be accidental or mislabelled from the vast data of collection in Japan and this species may not be distributed in the mainland of Japan.

Biological notes. Most of the type specimens of this species were collected from sandy soil in the She-oak (Casuarinaceae, Casuarina spp.) stands, pine woods and subtropical broad-leaved forest. The other individuals (males only) captured by light trap.

\section{Acknowledgement}

I wish to express my sincere thanks to the late Dr. Kintaro Baba for his kind offer of the materials and assistance. My cordial thanks are due to Prof. Katsura Morimoto and Associate Prof. Osamu Tadauchi of the Entomological Laboratory, Kyushu University for their encouragement and continuous guidance. I am also indebted to Dr. Iwan Löbl, Dr. Kazuo Ogata, Mr. Yukihiko Hirano, Mr. Hisashi Ohishi and Mr. Hiroaki Kojima for their submitting the invaluable specimens used in this work.

\section{Reference}

Nomura, S., 1991. Systematic study on the genus Batrisoplisus and its allied genera from Japan (Coleoptera, Pselaphidae). Esakia, Fukuoka, (30): I-462. 